Perspectiva Geográfica

ISSN 0123-3769 (Impreso) - 2500-8684 (En línea)

Vol. 21 N. ${ }^{\circ} 2$ de 2016

Julio - Diciembre

pp. 345-372

\title{
La inmigración indocumentada por países de tránsito, nuevo paradigma de los sistemas migratorios: el caso de México y Marruecos
}

\author{
The Undocumented Immigration by Transit Countries, New \\ Paradigm of Migratory Systems? The Case of Mexico and \\ Morocco
}

\section{Jorge Antonio Morales Cardiel ${ }^{1}$}

Para citar este artículo utilice el nombre completo así:

Morales-Cardiel, J. A. (2016). La inmigración indocumentada por países de tránsito, nuevo paradigma de los sistemas migratorios: el caso de México y Marruecos. Perspectiva Geográfica, 21(2), 345-372. doi: 10.19053/01233769.5857

\section{Resumen}

La principal motivación de este trabajo parte de la intensión de comprender el estado actual en que se encuentran la migración indocumentada en los países de tránsito, a través de la teoría de los sistemas migratorios, en específico de México y Marruecos. Un dilema que tiene su origen en la irregularidad normativa del inmigrante indocumentado, que se traduce en la ausencia de condiciones legales de las personas que deciden trasladarse fuera de las fronteras nacionales, por la carga implícita que posee la inmigración indocumentada o no autorizada de incumplir con los requisitos del país de

1 Estudiante de Doctorado en Estudios del Desarrollo. Universidad Autónoma de Zacatecas. México Máster Oficial en Migraciones Internacionales, Investigación, Políticas Públicas y Mediación Intercultural. Miembro de Asylum Access, Latinoamérica. jorgemcardiel@gmail.com 
tránsito y de destino. Una consigna que, más allá del célebre derecho humano universal a la libre movilidad, arroja una cuestión sobre si en efecto existe la intención de dotar de los derechos más elementales al inmigrante durante el tránsito hacia su destino.

Palabras clave: Derechos Humanos, inmigración indocumentada, países de tránsito, políticas públicas, sistemas migratorios.

\begin{abstract}
The main motivation on this work, arises from the intention to understand the current condition about undocumented immigration in transit countries, through the theory of migration systems, specifically in Mexico and Morocco. This is a "dilemma" which has its origin in the irregularity of regulations to interpret the lack of legal conditions for people who decide to move outside of national borders in order that the "implicit" quantity that has undocumented or nonauthorized immigration. Such a procedure, beyond the celebrated universal human right to free-movement, raises another question: Is there any intention to endow fundamental rights to immigrants during their journey towards their destination?
\end{abstract}

Keywords: Humans Rights, Migration, Public Policies, Transit Countries, Undocumented. 


\section{Introducción}

México y Marruecos atraviesan un nuevo paradigma migratorio al experimentar un cambio con relación a sus patrones, pasando de ser los tradicionales países de expulsión migratoria a convertirse en países de tránsito de las migraciones indocumentadas. En el caso de México, las migraciones centroamericanas y para Marruecos, las migraciones subsaharianas.

La relación que sustenta la nueva fase de la migración entre ambos países se encuentra en los intentos de alcanzar un mayor nivel de desarrollo económico, circunscribiéndose al modelo neoliberal que dictaminan las regiones más desarrolladas. Para México, la región correspondiente a América del Norte, con Estados Unidos a la cabeza, y para Marruecos, la Unión Europea, con España como puerta de entrada. Estos países dictaminan las directrices políticas hacia sus vecinos del sur, decretando las medidas adoptadas para vigilar y persuadir a los contingentes de personas que intentan atravesar sus territorios. Esto conlleva la asimilación de un control externalizado de fronteras en constante detrimento de los derechos humanos. Una consigna que, más allá del célebre derecho humano universal a la libre movilidad, arroja una reflexión fundamental: de si, en efecto, existe la intención de dotar al inmigrante de los derechos más elementales durante el tránsito hacia su destino, y si estos mismos derechos humanos no están erosionando la legitimad de los Estados tanto de tránsito como de destino, ante la incapacidad de controlar adecuadamente los flujos de migración.

Una cuestión de primer orden para entender la relación que aquí se plantea es reducir la ubicación geográfica entre México y Marruecos, y situarlos en el locus que más trasciende en la actualidad, el geopolítico, este locus trata de analizar dos sistemas migratorios comparando su situación interna hacia los derechos humanos con los inmigrantes indocumentados. En otros términos, dos países y dos sistemas migratorios que han evolucionado y que al inicio de este siglo se encuentran ante la transformación de su patrón migratorio interno, distinto al patrón habitual que se presentó por décadas, pasando de ser los tradicionales expulsores de migrantes a convertirse en países de tránsito de las migraciones. 
Propuesta teórica de sistemas migratorios

Para definir la propuesta del sistema migratorio, es necesario comprender que la mayoría de las migraciones corresponden a la desigual distribución espacial del capital y del trabajo, asumiendo como el origen las disparidades entre los niveles salariales de los países que intervienen, reflejado en los niveles de ingreso y bienestar (Arango, 2003). Esta afirmación se vale del pensamiento más clásico de las migraciones, que en la actualidad es criticado por obsoleto, como dice Arango, por quienes ven los procesos y los fenómenos sociales en términos de conflicto y no de equilibrio. Pero, sobre todo, es criticado porque considera a todos los migrantes indiscriminadamente, y a todas las sociedades implicadas como si fueran homogéneas, cuando no lo son.

La argumentación y propuesta del sistema migratorio que aquí se plantea se encuentra relacionada con las diferentes teorías migratorias que sobresalen en la actualidad. Una correlación que se basa en aspectos estructurales clásicos además de los nuevos enfoques conceptuales de corte antropológi- co que empiezan a trascender, los mismos que apuntan hacia el empoderamiento del migrante. Es decir, una perspectiva que combina el aspecto micro, que trata de la decisión individual de migrar considerando la diversidad del inmigrante, sus motivaciones para trasladarse desde su lugar de origen y sus efectos en el lugar de tránsito y destino, con las determinantes estructurales clásicas de un nuevo orden internacional por las dependencias entre naciones en el aspecto económico. Al comparar dos sistemas migratorios distintos no parecería lógico limitarse a una sola teoría de las migraciones y subsumir el concepto de sistema migratorio, tal como afirman Vidal y Martínez (2006), sobre la necesidad de mantener una amplia perspectiva de "sistema migratorio" para comprender el carácter multiforme de los procesos migratorios y la densidad de su gestión.

En esta investigación intervienen ambos enfoques teóricos, que no dejan de estar compuestos en la realidad por un núcleo de países desarrollados y una periferia de países en vías de desarrollo, vinculados por relaciones asimétricas de producción. Como menciona Arango (2003), supeditados al "desarro- 
llo económico con oferta limitada" (p. 5) que presenta diferentes grados entre las naciones, pero a fin de cuentas insertos en economías en desarrollo (Lewis, como se citó en Arango, 2003).

En estos sistemas económicos de acumulación de capital en los espacios geográficos por donde emergen los sistemas migratorios está presente, junto con la división del trabajo, el intercambio de bienes y el flujo de capital del mismo trabajo. Ha evolucionado hasta exhibir una de las principales características de estos sistemas internacionales de las migraciones en la actualidad: la circulación de trabajadores, donde la libertad de movimiento es la excepción y su restricción es la norma (Arango, 2003).

Las aportaciones de las diferentes teorías propuestas para las migraciones, en la lupa de Arango, permiten definir lo que es un sistema migratorio:

[L]os espacios definidos por la asociación relativamente estable de una serie de países receptores con un número determinado de regiones de origen. Estas asociaciones se dirigen más allá de las corrientes migratorias porque se ven constantemente reforzadas por conexiones y vínculos de distinta naturaleza. Sin embargo, el enfoque inspirado en sistemas migratorios, que aspira a explotar el potencial analítico de sistemas en general, constituye por el momento, poco más de un desiderátum no realizado, al menos en lo que concierne a migraciones internacionales. (Arango, 2003, p. 21)

Rastreando el origen del concepto de sistemas migratorios (pero a partir del desiderátum no realizado), es probable encontrarlo si nos remontamos hasta el decimonónico trabajo del geógrafo Ernest George Ravenstein, con las entrecomilladas "Leyes de la migración de Ravenstein". No obstante, de haber partido del estudio demográfico de la población, sus postulados han servido para definir tanto patrones de movimiento como para generar una estructura básica en el estudio de las migraciones, a pesar de no haber alcanzado la rigurosidad teórica de la ciencia.

El hecho de que un siglo después sigan vigentes las leyes de Ravenstein, a pesar de que el fenómeno migratorio se tornara multifacético y multidimensional, nos indica que 
los esfuerzos por tratar de orientar el estudio teórico de las migraciones han sido dispersos pues no ha sido tratado de la misma forma por geógrafos, sociólogos, economistas, politólogos, demógrafos e inclusive por juristas, y también porque estas leyes fueron recibidas con beneplácito por la comunidad académica para ser consideradas como punto de partida para encontrar un marco teórico de las migraciones.

Sin importar el devenir histórico de la movilidad espacial humana desde el siglo XIX, cuando Ravenstein argumentó sus postulados, la teoría de los sistemas migratorios se ha mantenido más o menos estable. Al respecto, Castles y Miller (2009), en el mismo sentido de la multidimensionalidad de las migraciones, señalan que no existe una causa determinada de las migraciones, sino una multiplicidad de las mismas. No obstante, todos se encuentran encausados a propiciar, facilitar y dinamizar estos movimientos migratorios.

Otro geógrafo que en la década de los setenta avanzaría considerablemente en la comprensión del concepto de sistema migratorio fue Akin L. Mabogunje (1970). Este se inspiró en la Teoría General de Sistemas del biólogo Ludwin Von Betarlanffy, quien entendía a los sistemas desde distintos niveles de la observación. Desde un punto de vista ontológico distinguió los sistemas reales de los sistemas conceptuales, estos últimos como construcciones simbólicas de la realidad. Bertalanffy entendía a la ciencia como subsistemas o sistemas abstraídos de los sistemas conceptuales en los que podemos situar a los sistemas migratorios. Afortunadamente, este mismo autor señalaría que la distinción entre sistema real y conceptual está sujeta a debate (Arnold y Osorio, 1998).

Mabogunje (1970) realizó estudios de las fuerzas y las energías que hay detrás de los movimientos migratorios rural-urbano en su natal Nigeria, pero también en el resto del África subsahariana. Mabogunje definiría el sistema migratorio como un conjunto de espacios vinculados por flujos y contraflujos tanto de personas -migrantes activos y migrantes pasivos (Hagerstrand, como se citó en Mabogunje, 1970)-, como bienes, servicios e información propensos a facilitar intercambios posteriores, siendo el más impor- 
tante la migración interconectada de personas.

Papademetriou y Boutang (1994), desde la década de los noventa, trataron de mostrar la coherencia de los diversos tipos de sistemas migratorios para poder definirlos. Se identificaron tres criterios que permitían definir lo que ellos denominaron como "regímenes migratorios": por un lado, estaba la oposición entre países de migraciones laborales y de poblamiento; otro, en la existencia de un régimen principal y un régimen secundario en el seno de todos los sistemas migratorios y, por último, el cierre a la apertura ante la emigración. Una combinación dinámica de los tres criterios se encuentra presente en el sistema marroquí y mexicano que abordaremos en las siguientes líneas, sin embargo, resaltar el penúltimo y el último criterio es indiscutible.

Estos mismos autores se dedicaron a la tarea de examinar las transformaciones de los sistemas que expusieron, para ellos estos se podían explicar a través de las inflexiones de las políticas migratorias. Esto se debe a que la política migratoria constituye un sub-sistema de cualquier sistema migratorio, pues incluye las acciones de los gobiernos centrales y locales, reflejando el contenido que posee el sistema, y también los componentes esenciales de su dinámica aún cuando la frontera entre sistema y política migratoria sea imprecisa en sí, sin estar muy seguros tampoco cuál determina a cuál. Lo que sí podemos afirmar es que las políticas migratorias son parte de los sistemas migratorios y no al contrario.

Es así como Papademetriou y Boutang (1994) denominan sistema migratorio a:

la combinación particular de tipos de flujo de población entre países de origen y países de llegada con las reglas y las leyes que rigen dichos flujos, y con las reacciones o contra-reacciones duraderas e institucionalizadas de los organismos que concurren a su mantenimiento o su extinción. (p. 4)

La argumentación anterior parece traer a colación la presencia de las políticas de control fronterizo aplicadas en ambos sistemas migratorios y sus subsecuentes resultados en la práctica de violación de derechos humanos, un aspecto incluyente en la actualidad en los 
sistemas migratorios. Izquierdo (2012) 1lama "políticas de control" a las prácticas que regularizan el volumen y naturaleza de los flujos en su doble dirección, sin descartar de la misma forma los derechos de integración.

Incursionando en la propuesta de marcar una diferencia entre las políticas de control de fronteras y las políticas de disuasión de la inmigración que se trabajan muchas veces de forma indistinta (marcada por una línea muy delgada que los divide), la política de control de fronteras pertenece a la vigilancia "en la raya" o "en la línea", con todos los mecanismos invertidos por los gobiernos receptores para reducir el flujo de inmigración. La política de disuasión abarca aspectos más amplios, desde la vigilancia interna hasta la externa, es decir, el control de flujos "hacia adentro" y "hacia afuera", como reafirmaba Cornelius (2012), con programas de regularización de la inmigración ilegal hasta las prácticas institucionales de "desgate por las sanciones" y de "desgaste por las devoluciones".

Ambas políticas migratorias tratan de contener la inmigración indocumentada. Ante "la ilegalidad" de las migraciones cabe reflexionar lo siguiente: si no hubiera la necesidad de buscar la alternativa indocumentada, producto de las desigualdades económicas, así como del marco jurídico de las naciones desarrolladas que terminan por consolidar medidas restrictivas de tipo proteccionistas, no existiría esta categoría de ilegalidad. En otras palabras, la ilegalidad es una condición impuesta por un marco normativo al momento de pasar las fronteras geográficas que delimitan dos Estados. Para Izquierdo (2012), la ilegalidad no forma parte de la naturaleza migratoria, no es una característica de la movilidad, sino el resultado de su tratamiento.

\section{Países de tránsito}

En la actualidad es muy característico que los países de tránsito apliquen políticas restrictivas de la movilidad territorial humana. Países tan lejanos entre sí, como México, Marruecos o Turquía, son guardianes de fronteras, es decir, países de tránsito de las migraciones de un tercer país, que cuentan con la peculiaridad de un dictamen de naciones más desarrolladas como Estados Unidos, España y Alemania respectivamente. Este dictamen opta por el endurecimiento de las 
políticas migratorias respectivamente a optar por el endurecimiento, de los sistemas migratorios en detrimento de los derechos humanos de los inmigrantes.

Para entender esta situación, es necesario conocer el término "país de tránsito" pues se ha convertido en el punto de inflexión, es decir, en un nuevo paradigma tanto para los sistemas migratorios como para las mismas inmigraciones indocumentadas. Además, es lógico que el léxico refiera a un punto intermedio que se encuentra entre un país de origen y un país de destino. El término "país de tránsito" es más bien político que económico o cultural, ya que no existe una categoría en el derecho internacional que lo reconozca. De ahí que el célebre Artículo 13 de la Declaración Universal de los Derechos Humanos peque de ser ambiguo al consagrar únicamente el derecho a salir y regresar al propio país, y de ser bastante tenue en el derecho universal de asentarse en un Estado que se elija libremente. Aunque se refiere a individuos que deban "elegir su residencia", sigue siendo atribución por parte del Estado reconocer este derecho.
Los países de tránsito constituyen por lo pronto una órbita geopolítica alrededor de todo el planeta, representan uno de los desafíos más importantes de la movilidad internacional actual y de las políticas públicas hacia la migración. Tanto migración como establecimiento atraviesan formas similares según Papadopoulou (2005), debido a esto el interés por definir a los países de tránsito viene en aumento. Es importante resaltar que para nosotros lo más relevante es que forman parte de los sistemas migratorios. En este sentido, para Marconi (2008) el tránsito debe ser en todo momento un proyecto migratorio temporal y limitado, aunque en la práctica muchas veces sea largo y semipermanente a consecuencia, precisamente, de las políticas restrictivas de los países de destino.

Un país de tránsito se define principalmente por la dinámica de los flujos migratorios, siendo su contención, la política, la jurisdicción y la temporalidad, los más importantes. Como apunta Marconi (2008), los países de tránsito son casi exclusivamente los que colindan con los países ricos, (y cita como ejemplo el caso salvadoreño, hondureño o nicaraguense). Una buena parte de la inmigración centroamericana que 
atraviesa por México para llegar a Estados Unidos, cruza por territorios pertenecientes a naciones que no son consideradas como naciones de tránsito pero en la práctica lo son, como es el caso de Guatemala. No obstante, en este sistema migratorio el espacio de tránsito por tradición le corresponde a México, en gran parte por la magnitud y evolución de los patrones migratorios y por la frontera que comparte con los Estados Unidos.

Por su parte, Ivakhniouk (2004) se refiere a las migraciones en tránsito como un punto intermedio que ocasionalmente se encuentra en condiciones inciertas e inseguras, lo que inexorablemente trae a cuenta la migración irregular o indocumentada, es decir, la condición de irregularidad que predetermina a la noción de país de tránsito. Tal como refiere Marconi (2008), no solo resulta casi imposible determinar el límite entre tránsito e inmigración indocumentada, sino que desafortunadamente el término "migración de tránsito" se ha convertido en un código para señalar a la misma inmigración indocumentada.

Por otra parte, el incremento de inmigrantes en situación irregular por países de tránsito ha demostrado la incapacidad en el manejo de las políticas públicas hacia la inmigración indocumentada. También, ha puesto en entredicho el reconocimiento por parte de gobiernos como el de México y Marruecos el haber suscrito tratados internacionales que reconocen los derechos humanos del inmigrante. Así, la clásica línea gubernamental en términos de la política fáctica tambalea ante el arribo de más inmigrantes en situación irregular, $\mathrm{y}$, sobre todo, denota la falta de gobernabilidad existente sobre el territorio.

Lo anterior se plantea como punto de partida para lo que podemos suscribir en la actualidad como el proceso de acompañamiento de las inmigraciones indocumentadas por países de tránsito, un proceso que vienen desenvolviendo en mayor medida las Organizaciones No Gubernamentales a favor de los derechos humanos a lo largo de los territorios de tránsito, sean de corte confesional o laico. El aspecto predecible del fracaso de las políticas públicas hacia la migración de control fronterizo, llevó a las autoridades gubernamentales a centrarse únicamente en aquellos aspectos que regulan únicamente 
el volumen y el origen de los flujos de inmigrantes.

\section{La construcción paradigmática de México y Marruecos como países de tránsito: el histórico fe- nómeno de violación a los dere- chos humanos}

\section{Sistema migratorio mexicano}

Por su ubicación geográfica, México es el único país latinoamericano que comparte frontera terrestre con los Estados Unidos, abarcando alrededor de tres mil kilómetros. De allí que históricamente este país tenga la mayor recepción de inmigrantes latinoamericanos: de origen mexicano hay alrededor de once millones, se calcula que cinco millones de ellos están de forma indocumentada, sin duda el flujo de migración indocumentada más numeroso en tiempos modernos.

Este flujo migratorio ha presentado periodos notables, como el correspondiente a la etapa de postguerra entre los años cincuenta y sesenta, con una migración relativamente mejor planeada. Para luego dispararse como nunca en la década de los ochenta y noventa, que tuvo como característica principal el ser una inmigración indocumenta- da alentada principalmente por la necesidad de mano de obra barata, preferida por el empresariado estadounidense debido a su bajo costo y su dócil manejo: ese "deseo apasionado de trabajo más barato y servicial" (Romero, 2010, p. 36) o esa migración "compulsiva y forzada” (López, 2013, p. 67).

Lo anterior llevó al endurecimiento de las políticas migratorias por parte del gobierno de los Estados Unidos en las últimas dos décadas, imputando una mayor vigilancia y persecución en la zona fronteriza. Esto se debió, además, a la sumisión del gobierno mexicano a que asumiera la responsabilidad no solo de cuidar el bienestar de sus connacionales, sino también el "bienestar" de los nacionales de un tercer Estado en su tránsito sobre el territorio mexicano, específicamente todo lo que a inmigración irregular centroamericana se refería.

La migración de tránsito por México en la década de los ochenta no representaba un asunto de mayor interés, hasta que se convirtió en un asunto de "seguridad nacional" para los Estados Unidos, lo que provocaría una fuerte demanda para que el gobierno mexicano controlara los flujos migratorios 
desde su frontera sur. La puesta en marcha de la "Operación sellamiento", en el mismo año (1993) de la creación del todavía vigente Instituto Nacional de Migración (INM), corroboraría el inicio de una política anti-migratoria hacia los indocumentados centroamericanos.

Otro tema incluido por sus repercusiones y efectos en aspectos políticos, económicos y de movilidad social en este sistema migratorio transnacional, es el North American Free Trade Agreenment (NAFTA) o Tratado de Libre Comercio de América del Norte (TLCAN), el acuerdo negociado entre los tres países de América del Norte: Canadá, Estados Unidos y México, anunciado desde el año 1991 pero que entró en vigor hasta el año 1994. Este tratado fue considerado en un principio como la única forma de disminuir las presiones migratorias al reducir el flujo de migrantes indocumentados.

El libre comercio y la inversión extranjera, a partir de ese momento, se convirtieron en el principal estímulo para la generación de empleos que permitiera retener el potencial de población migrante como una suerte de codesarrollo.
Esta apuesta la han venido realizando prácticamente los últimos cuatro gobiernos federales mexicanos, desde la apertura del NAFTA a principio de la década de los noventa, bajo un contexto de acumulación de capital asimétrico entre ambas fronteras, con una demanda sistemática de mano de obra mexicana y, en consecuencia, la expulsión de la población desempleada.

El incremento de muertes en esta región transfronteriza entre México y Estados Unidos ha ocurrido a partir de la implementación de la Operación Guardián (operation gatekeeper) el primero de octubre del año 1994, debido a la militarización y la construcción de un muro fronterizo entre los estados de California y Baja California. Esto obligó a los migrantes mexicanos y centroamericanos que deseaban "cruzar la línea", a optar por medidas más drásticas y peligrosas, como por ejemplo intentar atravesar el desierto entre Arizona y Sonora de la mano de traficantes de personas o "coyotes".

Esta extensión de la política estadounidense anti-inmigratoria (como lo fue la Operación Guardián), asentaría como resultado otro lamentable hecho que empeoró 
la situación fronteriza: la presencia de bandas criminales cuyos hechos han hecho víctimas del secuestro y asesinato a quienes buscaron el afamado "sueño americano", violando sistemáticamente, en concierto con las autoridades mexicanas, los derechos humanos de los indocumentados en la frontera.

Estos eventos encaminaron la inmigración irregular al tráfico ilegal de personas por las mafias o redes organizadas que dieron origen a la figura del "coyote" o "pollero", término que denomina a aquellos individuos que asisten el cruce de la frontera de forma ilegal. Los "coyotes" se multiplicarían por aquellos años a causa de la negligencia e inacción política del gobierno mexicano, a un grado tal que la actividad del tráfico ilegal de migrantes echó raíces entre la sociedad hasta ser parte de ella, e inclusive hasta ser partícipe de esta red trasnacional del sistema migratorio.

Lo cierto es que la política norteamericana anti-inmigrante no resultó ser accidental. Noam Chomsky (2009) anticipó que abrir la economía de México y del triángulo de Centroamérica a una avanzada lucha de importaciones agroindustriales, tarde o temprano, minaría a la agricultura, altamente subsidiaria y que las empresas apoyadas por el Estado no aguantarían la competencia frente a las enormes corporaciones de los Estados Unidos. Una consecuencia palpable resultó ser la huida de miles de personas a territorio estadounidense que junto a la migración centroamericana, incrementada por el terrorismo "reaganista" desde mediados de los ochenta, hizo de la Operación Guardián un remedio natural.

Era evidente por aquel entonces que la desconfianza de los Estados Unidos echaba raíces por doquier. Además, se sabía de antemano la ineficiencia mostrada por los gobiernos mexicano y centroamericano ante los problemas internos, y ante un posible colapso en el sistema económico que traería como consecuencia una nueva inmigración masiva de trabajadores indocumentados. Históricamente, el gobierno de Reagan consideró a la inmigración irregular como un problema que atentaba contra la seguridad nacional interna. La Ley Simpson-Rodino (IRCA) del año 1986, era un ejemplo de esta preocupación: consistía en un conjunto de sanciones a empleadores que contrataran trabajadores indocumentados, así como un recio 
control fronterizo. Sin alternativas, los Estados Unidos al finalizar el siglo XX se vieron en la necesidad de trazar la raya: hold the line.

Este y otros elementos de la agenda política mexicana-estadounidense en materia de migración tendrían su apertura al inicio de la primera administración del conservador Partido Acción Nacional (PAN), que tomaba la estafeta del Partido Revolucionario Institucional (PRI) después de 70 años de gobierno. Todo partía de la propuesta a su par estadounidense de una agenda binacional en materia de migración. A dichas negociaciones a posteriori se les conocería, en algunos círculos académicos y políticos estadounidenses, de manera peyorativa, como "la enchilada completa" o the whole enchilada. Esta incorporaba cinco "ingredientes":

1. Regularizar la situación migratoria de los más de cinco millones de mexicanos indocumentados que viven en Estados Unidos.

2. Establecer un programa de trabajadores temporales que permita el acceso autorizado de la fuerza laboral mexicana a regiones y sectores específicos de los mercados de trabajo a los Estados Unidos. ${ }^{2}$

3. Acordar una relación migratoria especial entre México y Estados Unidos para ampliar las visas disponibles a los mexicanos, con el fin de acercar su número a la realidad migratoria actual entre ambos países.

4. Fortalecer la seguridad fronteriza mediante acciones coordinadas entre México y Estados Unidos, haciendo especial énfasis en la lucha contra el tráfico de personas y a prevenir las muertes de migrantes en la frontera común.

5. Impulsar programas de desarrollo regional en las zonas de más alta intensidad migratoria en México, y articular estos esfuerzos con la instrumentación de un eventual programa de trabajadores temporales entre ambos países.

Las negociaciones en materia migratoria al inicio de la primera administración panista representaron un carácter inédito, pues aun siendo el vecino "sureño", siempre desfavorecido y proveedor de mano de obra barata, fue sorpresa que el mis-

2 Emulando al Programa Bracero, vigente del año 1942 al año 1964. 
mo pusiera en la mesa los acuerdos del tema. Esto sin contar el interés que despertó y las amplias expectativas en los círculos gubernamentales y en algunos sectores de la comunidad migrante en su momento, de ahí el carácter peyorativo de "la enchilada completa”.

No obstante, como señala Delgado (2003) y Morales (2014), "la enchilada completa" adolecía de importantes restricciones. Por ejemplo, descartaba una demanda esencial para acabar con el flagelo de las violaciones a los derechos humanos y laborales de los inmigrantes irregulares, que año tras año intentaban cruzar la frontera, y de quienes a su paso les seguían: los centroamericanos. Contar con dicha demanda hubiera tenido un peso importante en el diseño de las políticas mexicanas hacia la inmigración de tránsito, y hubiera brindado la oportunidad al gobierno mexicano de haber formado una base de credibilidad en defensa de los inmigrantes.

En la actualidad, la ausencia de leyes no es lo que explica el origen de la mayoría de los males que aquejan al inmigrante indocumentado en tránsito. Para la muestra, la reciente Ley de Migración que entró en vigor en mayo del 2011, establece las nuevas condiciones de estancia en el país para el inmigrante indocumentado. Desafortunadamente, tras cuatro años de su implementación, la Ley de Migración no resultó ser el "parteaguas" que los diferentes actores de la inmigración esperaban para detener las constantes violaciones a los derechos humanos de las personas inmigrantes. Esta Ley deroga las disposiciones en materia migratoria del anterior reglamento que contenía la Ley General de Población. De la misma forma se abrogan las disposiciones administrativas internas y las de carácter general expedidas por el Instituto Nacional de Migración, en materia de control, regulación y verificación migratoria, así como las disposiciones administrativas expedidas por la Secretaría de Relaciones Exteriores (SRE) en materia de expedición de visas (Ley General de Población, 2011).

La reglamentación parte de una política migratoria desde donde se tomarían decisiones estratégicas para atender al fenómeno migratorio de manera integral, así como para regular el ingreso y salida de mexicanos y extranjeros en un marco de respeto hacia los derechos humanos 
(Ley General de Población, 2011). Esta Ley permite la evolución de la figura legal del inmigrante hacia otro estadio cualitativo, despenalizando la inmigración irregular. Además, trata de reconocer al inmigrante como sujeto de derechos, independientemente de su situación migratoria, y sin importar estar al margen del sistema jurídico. En teoría, el inmigrante dejaría de carecer de derechos para su defensa. Quizás sea muy pronto para juzgar sus resultados, pero no dejará de ser importante tener en cuenta que esta nueva reglamentación se desprendió de un fenómeno socio-político producto de una fuerte presión social. Fue precedida de uno de los puntos más álgidos de la violencia contra la inmigración indocumentada, a raíz de uno de los acontecimientos más atroces del año 2010 que ocasionaron la muerte de 72 migrantes de diferentes nacionalidades en el municipio de San Fernando, en el Estado fronterizo de Tamaulipas a manos de la delincuencia organizada.

\section{Sistema migratorio marroquí}

Antes de que los países de Europa occidental cerraran sus fronteras a raíz de la crisis del petróleo de los países árabes en el año 1973, en el periodo correspondiente al año 1965 y 1972 el número estimado de marroquís en Europa crecía de manera notable. De Hass (2007) estimaba que el incremento de los marroquíes en el exterior pasó de 30.000 a 300.000. Las transformaciones demográficas de los años setenta en Marruecos fueron acompañadas a nivel interno por el fenómeno de la transición del sistema agrario. Un sistema agrario marroquí estaba basado en el monopolio de la escritura, dentro de una democracia comunitaria de clanes donde predomina el estilo de vida rural, para dar paso a una sociedad caracterizada por la escolarización masiva en las zonas urbanas y una movilidad espacial y social, denotando una fuerte injerencia del Estado (Roque, 2004). ${ }^{3}$ Es sabido que el Estado Marroquí, desde su independencia en el año 1956, impulsa una política migratoria en determinadas regiones como consecuencia de la movilidad de personas que además posee un carácter de tipo económico (De Hass, 2007).

Refass (como se citó en De Hass, 2007) distinguía principalmente tres "cinturones de emigración": (1) la parte del área montañosa del

3 Roque (2004) se basa en los estudios del antropólogo y estudioso de Marruecos Ernest Gellner. 
Rif, (2) la región suroccidental del Souss y (3) los oasis localizados al sureste del Alto Atlas. En estos lugares, el gobierno marroquí reconocería factores de inestabilidad social que solo una política migratoria podría tener, en términos de aliviar las tensiones, mediante la promoción de la emigración de estas regiones especialmente la turbulenta región del Rif, hablante del Bereber. Se trataba de un importante viraje en la política migratoria marroquí, ya que durante el reinado de Hassan $\mathrm{II}^{4}$ fue bien conocida la mano firme y arbitraria hacia los disidentes dentro y fuera del país (Yrizar, 2009). Las personas nacionales de Marruecos en el extranjero eran una suerte de ejército de opositores para el reino.

La emigración en Marruecos fue exponencial hasta la década de los noventa, cuando, de acuerdo con la información del Ministerio de Asuntos Exteriores y de la Cooperación de Marruecos, el número de nacionales en el extranjero pasó de 1,31 millones en el año 1995 a 2,2 millones en el año 2001, repartidos principalmente en países europeos

$4 \quad$ Hassan II, Rey de Marruecos desde el año 1961 hasta su muerte en el año 1999. Perteneciente a la dinastía alauí, reinante actual en Marruecos, y padre del actual monarca Mohamed VI. como Francia, Holanda, Bélgica, Italia, Alemania y España (Yrizar, 2009). Este crecimiento demográfico influyó en el panorama político del país, en torno a la atención del gobierno del rey Mohammed VI hacia sus emigrantes internacionales, haciendo eco de las demandas sociales heredadas desde el reinado de Hassan II, lo que significó el delicado trance de una monarquía absoluta hacia la democratización del país (Jiménez, 2012). A partir de entonces, la política migratoria de Marruecos se centraría en sumar a los emigrados al desarrollo de su país, debido al incremento en cifras y a la paupérrima democratización impuesta mediante tratados con la Unión Europea.

El proceso de apertura económica iniciado en el año 1983, con la firma de un acuerdo con el Fondo Monetario Internacional para liberalizar la economía, influiría en la democratización de una monarquía como la marroquí, y el codesarro1lo con los emigrantes. La apertura se profundizaría en el año 1987 con la adhesión de Marruecos al Acuerdo General sobre Aranceles Aduaneros y Comercio (GATT, por sus siglas en inglés), y con el ascenso de Mohammed VI en el año 1999, emprendiendo una am- 
plia reforma política y económica con la puesta en marcha del Plan Nacional de Desarrollo Económico y Modernización (Barajas, 2001).

A través de esos años, y con el éxodo del campo a la ciudad, a nivel interno se darían nuevos procesos de reagrupamiento en una sociedad disgregada por el desgaste de las instituciones tradicionales de Marruecos. Con una creciente clase media, pero también ante la exclusión de amplias capas de población, aparecieron en el vocabulario político del país cuestiones esenciales como los estatutos de derechos de las minorías, acompañadas por organizaciones en defensa de los derechos humanos (Roque, 2004). Esto llevaría Ipso facto, a que resaltara de igual forma la precaria situación en la que se encontraban los inmigrantes subsaharianos durante su tránsito y estado de sitio por este país. Según Cebrián y Charef (2012), desde la década de transformaciones sociopolíticas de los años setenta, se tiene conocimiento de la existencia de inmigraciones clandestinas de subsaharianos atravesando el territorio de Marruecos.

La policía española de las ciudades de Ceuta y Melilla, localizadas en territorio marroquí, han proporcionado datos acerca del número de inmigrantes que han interceptado después de intentar saltar las vallas que rodean estas ciudades. El gobierno marroquí estima que 3.000 han sido los inmigrantes interceptados para el año 2012. Para las delegaciones españolas la cifra se sitúa en torno a los $4.500 \mathrm{y}$ 5.000 detenidos (APDHA, 2013). Tanto el gobierno español como el marroquí están coordinados por el dispositivo de Frontex. ${ }^{5}$ Esta coordinación entre España y Marruecos se hace presente en las intercepciones y devoluciones de inmigrantes subsaharianos "en caliente", debido en gran parte a un aumento de las relaciones diplomáticas de ambos países desde mediados del año 2004, cuando se establecieron patrullas mixtas para luchar contra el tráfico en el Estrecho y en la costa oeste de Marruecos (Román, 2012).

El lamentable estado existente en esta zona de la inmigración indocumentada está íntimamente ligado al endurecimiento de las medi-

$5 \quad$ La agencia de fronteras exteriores de Europa, creada en 2004 con sede en Varsovia, tiene como misión la coordinación, vigilancia y análisis de la frontera europea. Según Román (2012), surge a partir de las revueltas originadas desde el año 2010 en el norte de áfrica, en Túnez, Egipto y Libia; la "Primavera Árabe". 
das de seguridad en los controles fronterizos por parte de Marruecos y España, que incide directamente en el tránsito de inmigrantes, pues buena parte de estos se encuentran sitiados en el territorio marroquí; aunque el destino final de su proyecto migratorio es el continente europeo. Entre las personas naturales de un país subsahariano, sea por desconocimiento, ausencia de información, o ante la imposibilidad de dar marcha atrás, una gran parte se encuentra bloqueada durante meses e incluso años en Marruecos.

Marruecos es y seguirá siendo el principal punto de partida para todos aquellos que intenten acceder a Europa desde el África occidental. Encontrándose próximos a la frontera con Ceuta y el monte Gururú, a través de once kilómetros de montaña para llegar a Nador colindante con Melilla, son muchos quienes deben malvivir a la espera de una posibilidad de acceder a ambas ciudades autónomas, sobreviviendo a condiciones de extrema precariedad y a merced de las esporádicas redadas de la policía marroquí (Lorenzo, 2004). Esta travesía está plagada de riesgos y dificultades para las personas que recorren los cientos de kilómetros del desierto del Sahara en condiciones de precariedad, trayendo como una desafortunada consecuencia la pérdida de vidas humanas. Se puede traer tan solo un ejemplo para entender estos riesgos: lo sucedido en octubre de 2013, cuando 87 inmigrantes murieron de sed en el desierto de Niger muy cerca de Argelia mientras recorrían el trayecto desde Agadez rumbo a Tamanrasset, 48 de estos inmigrantes eran niños, 32 mujeres y 7 hombres ("Hallados 87 migrantes muertos", 2013).

De esta forma, los tradicionales cinturones de emigración de población marroquí, según Refass (como se citó en De Hass, 2007), se han transformado en las últimas décadas en los territorios de tránsito y bloqueo temporal de las inmigraciones subsaharianas, especialmente la región del Rif, al norte de Marruecos y próxima al estrecho de Gibraltar, bajo protectorado español desde el año 1913 hasta el año 1956.

Román y Shirk (2012) señalan acerca de las características geográficas de esta frontera, su proximidad y brecha económica entre Europa y África como el factor determinante de una suerte de laboratorio donde ensayar políticas 
de gestión fronteriza de la Unión Europea; así como el factor de la condición de Ceuta y Melilla como territorios no adheridos al Tratado Schengen, y la confluencia del entorno en que se desenvuelve el Estrecho, bajo la jurisdicción de tres Estados: España, Gran Bretaña ${ }^{6}$ y Marruecos.

La coacción de las autoridades marroquíes se debe en gran parte a la presión de la Unión Europea (UE) para el control de los movimientos migratorios de la población subsahariana. Una nueva Ley en materia de extranjería, elaborada por el gobierno de Mohamed VI, obedece la lógica de seguridad penalizando a los extranjeros en situación irregular (Lorenzo, 2004). Este nuevo escenario para Marruecos adquiere una doble dimensión: Lorenzo (2004) plantea que se debe hacer frente a las presiones de la UE para frenar sus propias dinámicas migratorias, a la vez que se deben responder aquellas imposiciones provenientes del resto del continente africano. Lo anterior sitúa a

6 Gibraltar es una colonia del Reino Unido, su soberanía fue transferida a la corona de Gran Bretaña en el año 1713 mediante el Tratado de Utrecht, tras la guerra de sucesión española. Este se ubica al este de la bahía de Algeciras, extendiéndose sobre la formación geológica del Peñón de Gibraltar, un islote rocoso unido a la península ibérica.
Marruecos en una difícil posición frente a sus vecinos europeos, especialmente frente a España y el resto de países africanos.

La gestión fronteriza en esta parte del estrecho del mediterráneo se ha convertido para la UE en uno de los principales temas de discusión. Hasta el momento, la discusión gira en torno a la aprobación de planes de acción para combatir la migración irregular, los acuerdos van por la vía de mejorar el impacto de la migración legal, no solo de la Unión Europea, sino también entre los países africanos (González, 2014). No es de extrañar que tras el dramático comienzo del año 2014 con la tragedia del espigón del Tarajal donde fallecieron 15 inmigrantes indocumentados, y como preámbulo del fracaso de la política de control de flujos de la UE a través del Estado español, Marruecos iniciara un ambicioso proceso de regulación de inmigrantes indocumentados, el primero de este tipo en un país africano (Casquero, 2014).

Todo lo anteriormente expuesto, según Jiménez (2012), debe enmarcarse dentro del fracaso cosechado por el proceso histórico de asociación euro-mediterránea en medio 
de la política europea de vecindad. Los objetivos de esta política dieron paso a la creación de una zona de libre comercio, de la promoción de la democracia y del tratamiento adecuado de los derechos humanos. No obstante, la falta de financiación para el desarrollo por parte de estos países, así como la falta de voluntad de los gobiernos, probó el enfoque limitado y poco convincente por parte de la UE sobre los procesos de asociación y sobre las relaciones con el Magreb.

\section{Los derechos humanos en la in- migración irregular}

Si hablamos de derechos fundamentales para los inmigrantes, pocos son los referentes para establecer un marco normativo favorable como el derecho reconocido en el artículo 13 de la Declaración de los Derechos Humanos. Como señala De Lucas (2006), el derecho de libre circulación, sin un correspondiente libre acceso, transforma a la mayoría de los inmigrantes en la medida de sus expectativas de "situarse en órbita", una órbita geopolítica en donde se localizan los países de tránsito.

La yuxtaposición entre la soberanía del Estado y el derecho al libre tránsito es un hecho que empobrece aún más la situación de las personas inmigrantes centroamericanas y subsaharianas (en México y Marruecos respectivamente). Sassen (2001) considera que estos principios, al estar asentados en esta doble base, interna y externa, hacen que el régimen de derechos humanos opere de manera parcial dentro de cualquier Estado nacional. No obstante, en palabras de esta misma autora, el Estado sigue representando el papel más importante en la elaboración y aplicación de las políticas de inmigración.

Cabe preguntarse ¿por qué la falta de coherencia aparece con mayor resonancia en el momento histórico en que nos encontramos? ¿Acaso las migraciones indocumentadas han puesto en tela de juicio los derechos humanos? Siguiendo la línea de diversos autores, el origen se encuentra en el mismo sentido en que se concibió este documento. Noam Chomsky, citando a Mary Ann Glendon, cuestiona que la declaración no conlleva de forma irrestricta a la universalización de los derechos del hombre tradicionales, sino que forma parte de un nuevo momento en la historia de los derechos humanos. Un momento que se desprende de los 
instrumentos legales creados tras la Segunda Guerra Mundial, que entre otras cosas intentaron modificar "la justicia social en el tronco del árbol de la libertad" (Chomsky, 2003, p. 58).

Entonces, ¿el origen de la coyuntura comienza por las contradicciones intrínsecas e históricas de los derechos humanos con los motivos de la movilidad espacial humana? $\mathrm{Si}$ se tratara exclusivamente de la concepción de la declaración, lo único que parece intrínseco en la actualidad, como profesa su preámbulo, es la irreconciliable relación con el derecho a circular libremente y elegir la residencia en el territorio de otro Estado. Esto expresa el Artículo 13 con los intereses políticos y económicos de los países desarrollados (Hunt, 2007).

Para Hunt (2007) los derechos humanos no van más allá de ser una pretensión, la declaración es una aserción que se da en momentos y lugares específicos. Esto sin contar la paradoja que subyace a cómo pueden ser los Derechos Humanos universales sino se reconocen universalmente. Hunt se alínea en el sentido ideológico de Chomsky cuando afirma que "existe el riesgo de que la historia de los derechos humanos se convierta en la historia de la civilización occidental" (Hunt, 2007, p. 19).

Por otra parte, si por las pretensiones de los inmigrantes fuera poner en tela de juicio el carácter universal de los derechos humanos, estos demuestran que el momento histórico en que nos encontramos ha evolucionado hasta tal punto, que los intereses de las naciones desarrolladas contrastan con el libre tránsito entre fronteras. Susan George (2003) manifiesta que el proceso de globalización neoliberal es incompatible con la globalización de los derechos humanos, porque la Declaración Universal de los Derechos Humanos está fundamentada en una ética colectiva, que establece las normas de una sociedad basada, a su vez, en los derechos humanos centrados; entre otras cosas, el respeto a la dignidad de las personas sin exclusión alguna. George reconoce que es difícil que con la globalización neoliberal (donde se transfiere a diario la riqueza de los pobres a los ricos), las personas del denominado "tercer mundo" puedan tener una vida decente con una igualdad de oportunidades que garantice un estilo de vida digno. 
El problema de la inmigración irregular para los países de tránsito $\mathrm{y}$ destino es un problema tanto jurídico como político. Hasta ahora los derechos humanos parecen no estar a la altura de lo que se espera cuando se eleva su tratamiento hasta ámbitos legales. Hay que considerar de antemano que los países desarrollados poseen un sistema de exclusión de facto; como afirma George (2003), su sistema ha sido diseñado por economistas de aguda condición occidental y neoliberal, dejando multitudes de grupos sociales al margen del desarrollo, entre ellos, los inmigrantes indocumentados.

\section{Conclusiones}

Durante las últimas dos décadas, la UE y los Estados Unidos han instrumentado acciones de algún modo similares y simultáneas para sus vecinos del sur. Ambos gobiernos han realizado esfuerzos discretos por incentivar el desarrollo económico y comercial de algunas regiones de Marruecos y México como una medida que intente frenar la migración. Pero mientras esperan a obtener buenos resultados, ambos países han aumentado de manera drástica las medidas de seguridad fronteriza con el fin de impedir la entrada de inmigrantes indocumentados de un tercer Estado.

Las medidas de seguridad instrumentalizadas y trasnacionalizadas por parte de los gobiernos de los países de destino hacia las migraciones de tránsito por México y Marruecos (tanto de centroamericanos como de subsaharianos, respectivamente), se encuentran ligadas a la historia de la migración indocumentada de sus respectivos contingentes. Ambos países de tránsito carecen de una base mínima de credibilidad política cuando fallan en la atención de los derechos de sus propias migraciones, un tema que fue aprovechado por sus vecinos del norte para definir la agenda migratoria hacia los contingentes de un tercer país. En otras palabras, ambos países de tránsito experimentan un control de fronteras asimilado desde el exterior: un control de fronteras en detrimento de los derechos humanos.

La intención de entrar en el terreno de las comparaciones y semejanzas de los sistemas migratorios nos permitió reconocer patrones migratorios dentro de los sistemas migratorios y no únicamente por el periplo geográfico. Comparar 
una frontera que se extiende a lo largo de $3.000 \mathrm{~km}$, entre EE.UU y México, con otra que solo abarca $60 \mathrm{~km}$, entre España y Marruecos, parecía algo complicado. Acá cabe resaltar el reconocimiento de las similitudes en el ámbito socio-político de ambas naciones, que viene agravando la situación de vulnerabilidad de los inmigrantes indocumentados en el tránsito hacia su destino.

Los sistemas migratorios examinados son sistemas contemporáneos que han evolucionado hasta tener como punto de inflexión los países de tránsito. En estos sistemas se ve reflejado el desarrollo de un proceso de restructuración económica de la globalización neoliberal. Desde la periferia del mundo subdesarrollado hasta el norte del desarrollo, la inmigración no se entiende en tanto un proceso de reestructuración de la sociedad, sino a estar sujetos a una rápida transformación socioeconómica, representada con el cambio del patrón migratorio. La política migratoria de los países de destino hacia los países de tránsito se ha caracterizado por el control restrictivo de la inmigración indocumentada, lo que apuntala el detrimento de los derechos humanos de los inmigrantes de un tercer Estado.

Los Derechos Humanos no parecen, de momento, cumplir las exigencias de un ámbito legal cuando se habla de migración. Sin embargo, en la actualidad, para los gobiernos de México y Marruecos resulta más fácil apoyar a los Derechos Humanos que su aplicación.

\section{Referencias}

APDHA. Asociación Pro Derechos Humanos de Andalucía (2013). Derechos humanos en la frontera sur. España. APDHA.

Arango, J. (2003). La explicación teórica de las migraciones: luz y sombra [Versión electrónica]. Red internacional de migración y desarrollo. Recuperado de http://migracionydesarrollo. org/

Arnold, M y Osorio, F. (1998). Introducción a los conceptos básicos de la Teoría General de Sistemas. Cinta de Moebio, (3), 40-49. Recuperado de http://www.revistas.uchile.cl/index. php/CDM/article/viewFile/26455/27748 
Barajas, M. (2001). Dos experiencias de cooperación bilateral y transfronteriza: Marruecos y México. En N. Ribas. (Ed.), El río bravo Mediterráneo. Las regiones fronterizas en la época de la globalización (pp. 189-207). Madrid: Ediciones Bellatera.

Casquero, J. (26 de febrero de 2014). Marruecos estrena regularización de inmigrantes y tensa el estrecho. El pais, p. 5.

Castles, S. y Miller, M. (2009). La era de la migración. Movimientos internacionales de la población en el mundo moderno. México, D.F.: Miguel Ángel Porrúa.

Cebrián, J. y Charef, M. (2012). La inmigración irregular española procedente de Marruecos. En J. Román y D. Shirk. (Coords.), 2 fronteras. Comparando las fronteras de Estados Unidos y España (pp. 73-98). San Diego: University of San Diego.

Chomsky, N. (2003). Recuperación de los derechos: un camino sinuoso. En J. Gibney. (Ed.), La globalización de los derechos humanos (pp. 49-87). Barcelona: Crítica.

Chomsky, N. (22 de septiembre de 2009). Guerras, drogas y política, elementos del mundo bipolar. La jornada, pp. 3-9.

Cornelius, W. (2012). Evaluación de la reciente política de control de la inmigración estadounidense: lo que los emigrantes mexicanos pueden contarnos. En A. Izquierdo y W. Cornelius. (Coords.), Políticas de control migratorio. Estudio comparativo de España y EE.UU (pp. 31-43). Madrid: Ediciones Bellaterra.

De Hass, H. (2007). Between Courting and Controling: The Moraccan State and 'its'Emigrants [Working Paper No. 54]. University of Oxford, Centre on Migration, Policy and Society.

De Lucas, J. (2006). El marco jurídico internacional de las migraciones. Algunas consideraciones sobre la protección de los derechos humanos de los inmigrantes: acerca del hecho de ser inmigrante. En F. Mariño Menéndez. (Coord.), Un mundo sin desarraigo: el derecho internacional de las migraciones (pp. 29-56). Madrid: Catarata.

Delgado, R. (2003). La agenda oculta de la administración foxista en materia migratoria. En México en el primer año de gobierno de Vicente Fox. México, D.F.: Miguel Ángel Porrúa.

George, S. (2003). ¿Globalización de los derechos? En J. Gibney (Ed.), La globalización de los derechos humanos (pp. 21-39). Barcelona: Critica.

González, C. (2014). La inmigración irregular y la Cumbre Euro-Africana. Comentarios Elcano. Madrid: Real Instituto Elcano.

Hallados 87 migrantes muertos de sed en el desierto de Niger cerca de Argelia. (30 de octubre de 2013). El País, p. 8.

Hunt, L. (2007). La invención de los derechos humanos. Barcelona: Tusquets. 
Ivakhniouk, I. (2004). Analysis of the economic, social, demographic and political basis of transit migration in Russia-Moscow Case. Paper presented at the Council of Europe Regional Conference on 'Migrants in transit countries: Sharing responsibility for management and protection', Istanbul 30 September-1 October 2004.

Izquierdo, A. (2012). La política de regularizaciones masivas y su función en el modelo migratorio español. En Políticas de control migratorio. Estudio comparativo de España y EE.UU (pp. 45-101). Madrid: Edicions Bellaterra.

Jiménez, C. (2012). Dilemas de las relaciones con Marruecos desde una óptica europea y española: una revisión de la teoría de la "paz democrática". En M. Acosta Sánchez y M. Remi Njiki. (Coords.), Inmigración, seguridad y fronteras. Problemáticas de España, Marruecos y la Unión Europea en el área del estrecho (pp. 195-243). Madrid: Dykinson.

Ley de Migración. (2011). Diario Oficial de la Federación. Cámara de Diputados del H. Congreso de la Unión, México. Ciudad de México. http://www.diputados.gob.mx/LeyesBiblio/pdf/ LMigra_301014.pdf.

López, V. (2013). Desarrollo, migración y seguridad: el caso de la migración hondureña hacia los Estados Unidos. Migración y desarrollo, (21), 65-104.

Lorenzo, M. (2004). Marruecos, país de tránsito y emigración. En Atlas de la migración marroqui en España. Taller de Estudios Internacionales Mediterráneos (pp. 58-61). Madrid: Universidad Autónoma de Madrid.

Mabogunje, L. (1970). Systems Approach to Theory of Rural-Urban Migration. Geographical Analysis, (2), 1-18.

Marconi, G. (2008). Ciudades de tránsito, guardianes del primer mundo. -Entre desafíos, contradicciones y compromisos- [Versión electrónica]. VI Encuentro anual de RedGob, Lisboa.

Morales, J. (2014). La enchilada Light. Revista San Gregorio de Portoviejo, (8), 85-90.

Papademetriou, D. y Boutang, Y. (1994). Sistemas y políticas migratorias: análisis comparativo de sus resultados. Desarrollo OCDE, (24), 21-43.

Papadopoulou, A. (2005). Exploring the asylum-migration nexus: a case study of transit migrants in Europe. Global Migration Perspective, 23, Global Comission on International Migration, Genova.

Román, J. (2012). La cooperación en la gestión de fronteras en el seno de la UE y con terceros países. En J. Román y D. Shirk. (Coords.), 2 fronteras. Comparando las fronteras de Estados Unidos y España (pp. 47-97). San Diego: University of San Diego.

Román, J. y Shirk, D. (2012). 2 fronteras. Comparando las fronteras de Estados Unidos y España. San Diego: University of San Diego. 
Romero, E. (2010). Un deseo apasionado de trabajo más barato y servicial. Migraciones, fronteras y capitalismo. Madrid: Cambalache.

Roque, M. A. (2004). Sociedad civil, solidaridad y desarrollo. En J. Lacomba. (Ed.), Migración $y$ desarrollo en Marruecos (pp.15-23). Barcelona: Catarata.

Sassen, S. (2001). ¿Perdiendo el control? La soberanía en la era de la globalización. Madrid: Edicions Bellaterra.

Vidal, F. y Martínez, J. (2006). Religión e integración social de los inmigrantes: la prueba del ángel. Madrid: CEIM; Universidad Pontificia de Comillas.

Yrizar, G. (2009). Políticas migratorias e instituciones hacia los marroquíes en el extranjero. ¿Amenaza política o panacea transfronteriza? Frontera Norte, 21(42), 53-77. 
Recepción: 5 de enero de 2016

Evaluación: 3 de noviembre de 2016

Aprobación: 5 de diciembre de 2016 